\title{
Karl Marx dan Konsep Perjuangan Kelas Sosial
}

\author{
Karl Marx and the Concept of Social Class Struggle
}

INDRIATY ISMAIL* \& MOHD ZUHAILI KAMAL BASIR ${ }^{1}$

\begin{abstract}
This article explores the history of the renowned world economic and political reformist, Karl Marx with a special focus on the social class concept. It also discusses to what extent that the Marx's concept of social class struggle is capable to provide a way out to the proletariats, to free themselves from the chains of cruelty, violence and alienation in the capitalist system. Our main focal point is to scrutinize the relationship between the concepts of social class struggle and the need for a social revolution as a catalyst for the formation of a classless society. Along the way, we studied and analyzed the documents produced on the primary sources covering major works of Marx and the secondary sources consisting reviews of the Marx's class concept. As a result, we found out that Marx's concept of class fight is competent to represent the oppressed group to battle for their freedom rights. The Proletariat dictatorship attitude was used as their main shield to face the threat of the capitalist class. Marx's ultimate success is realized through a burst of ideas and beliefs that supports the ideas of egalitarian Communism although many contradictions arise between the ideas of Marx and the 20th centuries Communism when they are translated into practice.
\end{abstract}

Keywords: Marx, social class, class struggle, socialist revolution, communism.

Abad kesembilan belas membuka lembaran sejarah kegemilangan di Jerman dengan kelahiran seorang tokoh hebat dunia yang memiliki pengaruh kekal dan kuat terhadap sejarah kehidupan manusia. Kekuatan pengaruh keintelektualannya telah menjadi fenomena global abad kedua puluh kerana gagasan pemikiran falsafahnya tidak hanya dijadikan sekadar rujukan ilmiah sahaja, tetapi segala idea dan teori-teori Marxisme digerakkan dalam bentuk tindakan yang realistik bersesuaian dengan keadaan semasa. Tidak hairanlah, jika Karl Marx (1818-1883) menduduki tangga kedua puluh tujuh dari seratus tokoh yang paling berpengaruh dalam sejarah (Hart 1993: viii). Salah satu sumbangan besarnya adalah konsep perjuangan kelas yang menjadi pemangkin kepada kaum buruh untuk bangkit mempertahankan hak dan kebebasan mereka dari terus menjadi 'kuda tunggangan' kaum kapitalis. Lantaran itu, ajaran Marxisme telah dijadikan pegangan perjuangan kaum buruh hampir ke seluruh dunia. Sebagai sebuah ideologi, Marxisme merupakan inspirasi bagi sebahagian besar gerakan pembebasan sosial dan beransur-ansur menjadi gerakan politik dan sosial di pelbagai tempat dan negara. Konsep Historical Materalism dan Dialectic Materialism merupakan ideologi utama yang melahirkan konsep kelas, hubungan antara kelas dan perjuangan kelas dalam gagasan pemikiran Marxisme.

\footnotetext{
${ }^{1}$ Indriaty Ismail*(corresponding author), Ph.D., Senior Lecturer at Department of Theology and Philosophy, Faculty of Islamic Studies, Universiti Kebangsaan Malaysia, 43600 BANGI, Selangor, Malaysia, email: indriaty@ukm.edu.my; Mohd Zuhaili Kamal Basir, M.A., Lecturer at Department Kampus Mukah, Universiti Teknologi Mara, KM7.5 Jalan Mukah-Oya 96400 Mukah Sarawak, Oya, 96300 Mukah, Sarawak, Malaysia, email: mohdz3506@sarawak.uitm.edu.my.
} 
Marx meneliti sejarah manusia dari dua aspek iaitu pertama, faktor ekonomi yang memaparkan rangkaian tahap perkembangan ekonomi manusia meliputi kaedah-kaedah mengeluarkan produk keperluan hidup dalam menentukan segala perubahan kehidupan manusia (A. Z. Abidin 1968: 46). Kedua, faktor sosial kerana Marx menggambarkan sifat semula jadi manusia yang suka bergaul. Namun faktor sosial tidak lengkap tanpa berhubung terus dengan faktor ekonomi kerana kehidupan sosial manusia tidak akan bertahan lebih lama melainkan manusia menghasilkan barangan atau produk untuk memenuhi keperluan hidup dan masyarakat sekelilingnya (Ozinga 1991: 40). Marx mengakui bahawa manusia lahir dalam era zaman yang berbeza-beza. Justeru itu, cara dan hubungan pengeluaran turut melalui tahap perkembangan kuasa-kuasa produksi material yang berbeza-beza. Setiap cara pengeluaran digambarkan dengan penguasaan kuasa produktif yang khusus dan satu bentuk hubungan sosial yang awalnya berfungsi untuk membangunkan kuasa tersebut. Aspek utama dalam hubungan tersebut adalah hubungan harta yang akan mewujudkan kelas-kelas sosial. Lantaran itu, muncul dua kelas utama berasaskan jenis-jenis harta yang mempengaruhi pengeluaran keperluan hidup. Satu kelas akan menguasai harta tersebut, manakala kelas lagi satu pula digunakan untuk menghasilkan kekayaan daripada harta tersebut (McLellan 1971: 93). Marx telah mengemukakan lima tahap cara pengeluaran yang berbeza-beza di mana setiap masyarakat perlu merentasinya iaitu tahap Komunis Primitif, Perhambaan Kuno (Classical Slavery), Feudalisme, Kapitalisme dan Komunisme (McLellan 1977: 256). Walau bagaimanapun, pembangunan dan kemajuan terhadap cara dan hubungan pengeluaran turut menyumbang usaha ke arah memacu daya inovasi dan kreativiti manusia melalui penemuan baru seperti penggunaan mesin wap, pembinaan kapal layar dan sebagainya. Cuma bagi Marx, keadaan tersebut akan menambah tekanan terhadap cara pengeluaran sedia ada kerana sejarah perubahan yang berlaku akan mewujudkan perjuangan kelas iaitu penentangan satu kelas ke atas satu kelas yang lain. Kesannya berlaku revolusi yang akan mewujudkan tahap baru bagi sejarah. Lantaran itu, kemuculan tahap baru akan melahirkan kelas atasan baru (new ruling class) yang akan menentang kelas bawahan yang terdiri dari kelas buruh dan petani. Maka tidak hairanlah jika kita meletakkan cara pengeluaran sebagai perintis terhadap kewujudan kelas sosial.

Hubungan antara manusia dan alam yang saling bertukar-tukar dan dikendalikan melalui cara pengeluaran khusus telah menghasilkan cara-cara dan keperluan-keperluan baru bagi memenuhi kemahuan masyarakat. Hubungan tersebut diabadikan oleh Marx dalam teori Dialectic Materialism yang menekankan tiga formula serangkai iaitu Theses, Anti-Thesis dan Syntheses. Contohnya, gambaran Marx tentang lima tahap cara pengeluaran iaitu tahap Feudalisme mewakili theses dalam zaman pertengahan. Apabila tahap Feudalisme dikontradiksi dengan kebangkitan kelas pertengahan iaitu kelas bourgeois, maka Kapitalisme dianggap sebagai anti-theses dan seterusnya diganti pula oleh tahap Komusnisme yang dianggap sebagai Syntheses. Proses 'dialektik' tersebut dijadikan senjata moral bagi perjuangan kelas buruh untuk membebaskan diri dari belenggu penindasan kelas kapitalis melalui proses revolusi (Lerner 1982: 37). Oleh demikian itu, sikap manusia itu sendiri dijadikan 'subjek' dialektik kepada perubahan sosial. Hasilnya, lahirlah organisasi buruh sosial dengan keperluan baru dan akhirnya kuasa produktif mereka mengalami peningkatan secara mendadak. Marx dan Engels menegaskan bahawa fenomena sosial termasuklah konflik-konflik yang berlaku dalam kelas sosial tercetus melalui siri-siri kontradiksi yang diimplementasi dari konsep dialektik tersebut (McLellan 1971: 152-153). Justeru itu, fahaman Dialectical Materialism dilihat telah berjaya mengorganisasi masyarakat dalam kelas-kelas sosial ekonomi dengan menyediakan kuasa-kuasa peralihan ke arah tahap tertinggi dalam perkembangan sejarah manusia. 


\section{Konsep Perjuangan Kelas dan Tuntutan Revolusi Terhadap Kelas Tertindas}

Antara pandangan sejarah Marx yang dianggap penting oleh pendukung aliran Marxisme adalah teori perjuangan kelas (Struggle of Classess). Dalam permulaan karya The Communist Manifesto (1972: 241), Marx telah mengungkap slogan:

The history of all hitherto existing societies is the history of class struggles. Freeman and slave, patrician and plebeian, lord and serf, guild-master and journeyman, in a word, oppressor and oppressed, stood in constant opposition to one another, carried on an interrupted, now hidden, now open fight, a fight that each time ended in a revolutionary reconstruction of society at large, or in the common ruin of the contending classes.

Menurut Marx, kelas-kelas tersebut merupakan kumpulan asas sosial yang mengheret konflik masyarakat di dalamnya dan memberi kesan kepada perubahan subskruktur ekonomi mereka. Lantaran itu, satu kelas mampu mengenal pasti kepentingannya di dalam masyarakat secara menyeluruh melalui revolusi-revolusi yang telah berlaku sebelum ini. Kenyataan Marx tersebut menggambarkan sejarah umat manusia diwarnai oleh perjuangan atau pertarungan antara kelompok-kelompok manusia. Marx sendiri mengakui perjuangan kelas atau revolusi yang tercetus bukan bermula sebagai satu kelas masyarakat, tetapi ia berfungsi sebagai wakil kepada masyarakat bagi mengemukakan tuntutan dan manfaat bersama semua ahli dalam masyarakat (McLellan 1977: 169).

Kecenderungan Marx untuk menganalisis idea-idea tentang teori kelas ditonjolkan dalam fasal terakhir karyanya iaitu Capital (jilid ketiga). Namun begitu, kematiannya pada tahun 1883 telah mengganggu proses penerbitan karya tersebut. Secara umumnya, konsep kelas sosial yang diutarakan oleh Marx telah diterjemahkan dalam versi sistem ekonomi Kapitalisme. Dalam karya tersebut, Marx telah membahagikan tiga kelas utama dalam struktur masyarakat kapitalis iaitu kelas buruh upahan (Wage Labourers), kelas kapitalis dan kelas pemilik tanah (Landowner), tetapi struktur tersebut masih belum kukuh walaupun wujud usaha kelas pertengahan untuk menghapuskan jurang pemisah antara kelas-kelas tersebut (Marx 1959: 504). Walau bagaimanapun, perkembangan struktur industri Kapitalisme hanya memperkenalkan dua jenis kelas sahaja iaitu bourgeois dan proletariat. Maka kesannya, semua kelas buruh upahan akan diklasifikasikan sebagai kelas proletariat, manakala kelas kapitalis dan pemilik tanah pula mewakili kelas bourgeois. Namun kedua-kedua kelas bourgeois tersebut terpaksa berhadapan dengan persaingan sengit dalam mengaut keuntungan dan kekayaan, lantas mereka yang tewas akan diletakkan di posisi kelas proletariat (McLellan 1971: 178).

Berdasarkan kenyataan di atas, kedua-dua kelas tersebut iaitu kelas poletariat dan bourgeois memiliki fungsi sosial yang berbeza-beza di mana kelas bourgeois memiliki alatalat produksi dan menguasai proses pengeluaran secara keseluruhannya, sedangkan kelas proletariat pula dianggap sebagai 'objek' dalam proses pengeluaran dengan menjual 'tenaga kerja' mereka dan mengenakan gaji atau upah yang rendah (McLellan 1977: 176). Jurang perbezaan antara dua kelas inilah yang menjadi punca kepada perjuangan dan penentangan antara kelas-kelas sosial. Tidak dinafikan, perkembangan masyarakat seringkali dikaitkan dengan polarisasi kelas iaitu satu kelas sentiasa berada di posisi bertentangan dengan kelas-kelas yang lain dan mengalami perpecahan, lantas kemudiannya akan membentuk dua blok yang saling bertarung (McLellan 1977: 222). Justeru itu, Marx menyifatkan sejarah manusia adalah sejarah pertentangan antara kelas yang menindas dan kelas tertindas. Kadang-kadang pertentangan tersebut dapat dilihat secara tersembunyi, tetapi adakalanya berlaku secara terbuka. 
Berhubung dengan kelas tertindas iaitu kelas proletariat, Marx dalam Poverty of Philosophy (n.d.: 214) menegaskan bahawa senario eksploitasi terhadap mereka telah melahirkan unsur 'antagonisme kelas' yang merangsang keinginan untuk bebas dari belenggu penindasan. Keinginan tersebut kemudiannya menjadi daya penggerak utama kepada mereka untuk membentuk sistem masyarakat sosial yang baru. Lantaran itu, sekiranya mereka berjaya menguasai kuasa-kuasa produktif, maka hubungan sosial pengeluaran sedia ada tidak lagi mampu mewujudkan kerjasama antara kedua-dua model kelas tersebut. Justeru itu, kuasa produktif mereka adalah kelas revolusioner itu sendiri. Kelas tersebut akan mendesak kepada perubahan struktur sosial melalui cara kekerasan dan kekejaman seperti perampasan kuasa secara revolusi. Ini kerana Marx mengharapkan kelas proletariat menjadi kelas penguasa apabila berjaya merampas kedudukan kelas bourgeois dan memusatkan segala alat-alat produksi di bawah genggaman kelas buruh.

Namun begitu, model kelas masyarakat baru yang bakal didirikan oleh kelas proletariat bukanlah bercirikan sistem kelas sosial feudalisme dan kapitalisme yang wujud sebelumnya. Sebaliknya, kebebasan yang dikecapi oleh kelas buruh hanya diimplementasikan untuk menghapuskan semua kelas masyarakat. Masyarakat tanpa kelas (classless) yang diperjuangkan oleh mereka merupakan titik permulaan kepada lenyapnya jurang pemisah antara kelas masyarakat dan kuasa pengeluaran akan jatuh ke tangan rakyat. Oleh yang demikian, sistem kekuasaan tersebut tidak lagi berfungsi sebagai alat penindasan terhadap masyarakat (McLellan 1977: 341). Sementara itu, permusuhan dan persengketaan antara kelas bourgeois dan proletariat hanya disifatkan sebagai perjuangan satu kelas menentang satu kelas yang lain hingga membawa kepada highest expression of total revolution.

Analisis Marx terhadap konsep revolusi secara amnya adalah berdasarkan kajian mendalamnya terhadap Revolusi Perancis terutama kegagalannya untuk memulihkan kejahatan sosial dalam proses pengagihan semula hasil kekayaan ekonomi negara. Kesannya, Marx telah mengutarakan konsep revolusi baru yang dinamakan sebagai Revolutionary Praxis iaitu gabungan konsep dan tindakan, gabungan elemen objektif dan subjektif dan penyatuan antara teori dan praktikal (Ozinga 1991: 53). Ini kerana Marx menjangkakan perubahan drastik ke atas golongan proletariat terutama kelas pekerja yang akan bangkit untuk mengatur semula dasar ekonomi masyarakat secara kolektif dan menggerakkan sebuah revolusi sosialis secara besar-besaran (Marx \& Engels 1976: 179). Meskipun begitu, Marx tetap meletakkan kejayaan revolusi tersebut adalah bergantung kepada usaha mobilisasi progresif dari kelas buruh itu sendiri, bukan mengharapkan bantuan kelas atasan seperti mana yang dilakukan oleh masyarakat Utopia pada abad ke 16 dan 17 Masihi.

Oleh sebab itu, Marx telah menentang komentar ahli sejarawan kelas pertengahan yang mengandaikan bahawa perjuangan kelas akan berakhir dengan kebangkitan kelas bourgeois. Ia merupakan respon kepada persepsi ahli ekonomi klasik yang menyifatkan sistem kapitalisme bersifat kekal dan berterusan. Ini kerana Marx menjangkakan kebangkitan kesedaran dan kuasa yang dimiliki oleh golongan proletariat industri akan dijana ke arah keadilan ekonomi yang masih mengekalkan perjuangan kelas dan perubahan revolusioner. Kenyataan Marx tersebut dibuktikan melalui pengutusan surat Marx kepada Weydemeyer (5 March 1852) di mana beliau begitu yakin bahawa perjuangan kelas bukanlah sebuah bentuk masyarakat yang kekal, tetapi ditentukan oleh perkembangan sejarah pengeluaran. Perjuangan kelas hanya akan ditamatkan melalui penghapusan sistem kapitalisme dan kewujudan masyarakat tanpa kelas (komunisme).

Selain itu, Marx dalam Address to the Communist League (1850) banyak menumpukan kepada idea 'permanent revolution'. Ia menjadi satu misi penting bagi kelas buruh untuk mempraktikkan revolusi tersebut sehingga kekuasaan negara benar-benar berada di dalam genggaman kelas Proletariat, meskipun agak sukar untuk menyesuaikan 
idea tersebut dengan perkembangan sistem politik yang bergantung sepenuhnya kepada dasar ekonomi masyarakat. Namun begitu, Marx mengiktiraf kepentingan faktor ekonomi dalam menentukan keberhasilan revolusi terutama ketika menjangkakan krisis-krisis ekonomi akan memprovokasi sebuah revolusi (Lichtheim 1961: 126-127). Contohnya, kejayaan revolusi proletariat akan dapat direalisasikan dalam sesebuah negara sekiranya majoriti populasi negara tersebut terdiri dari golongan petani berikutan krisis kos cagaran tanah yang tinggi dikenakan kepada mereka oleh pemilik tanah.

\section{Taktik Perjuangan Kelas Proletriat dan Kecenderungan ke Arah Pembentukkan Gagasan Komunisme}

Taktik perjuangan kelas yang digunakan seringkali menjadi isu perdebatan antara pemikirpemikir Marxisme selepasnya. Taktik tersebut merujuk kepada konsep 'Dictatorship of Proletariat'. Konsep tersebut menjadi kunci utama dalam memahami teori Marx berkenaan bentuk masyarakat komunis dan fungsi negara proletariat. Marx dan sahabatnya Engels menyifatkan negara yang dijadikan alat dominasi dan penindasan kelas akan berkembang kukuh serta kekal menjadi negara-negara minoriti yang mewakili minat kelas-kelas kecil (Bobbio 1979: 173). Marx lebih selesa merujuk konsep Dictatorship of Proletariat kepada penyataan tentang ciri kuasa politik kelas bukan bentuk kuasa kerajaan, meskipun kadangkala melibatkan kedua-duanya. Justeru itu, bentuk kuasa politik akan mempengaruhi dan mewarnai perwatakan sesebuah kelas masyarakat. Marx melihat peristiwa Paris Commune sebagai aksi pemberontakan pertama bagi kaum proletariat dalam industri moden dan menjadi model perjuangan antara golongan kapitalis dan buruh (Hook 1975: 177).

Marx dan Engels dalam karyanya The Communist Manifesto (1970: 74) telah mengemukakan Political Rule of Proletariat yang menyarankan agar golongan proletariat menakluki pertadbiran negara agar mereka boleh memanfaatkan kuasa politiknya untuk merampas semua modal dari cengkaman golongan bourgeois dan memusatkan semua alatan produksi di bawah kekuasaan negara yang ditadbir oleh golongan Proletariat sendiri. Ini dilihat sebagai usaha mereka untuk memusnahkan keistimewaan-keistimewaan yang dimiliki oleh golongan bourgeois. Berdasarkan pengalaman dalam Revolusi Perancis 1789, Marx telah mendesak kaum proletariat untuk merampas dan menguasai kepimpinan negara bagi menjadikannya lebih demokratik dan majoriti. Meskipun istilah 'diktator' ke atas undang-undang proletariat menjadi perbahasan dari pendukung aliran Babouvis-Blanguist, namun Engels menegaskan bahawa elemen 'diktator' amat perlu sebagai tindak balas kepada pelan kemusnahan kerajaan lama untuk mewujudkan kerajaan yang baru (Mukherjee \& Ramaswamy 2000: 126).

Idea komunisme mula diperkenalkan dalam gagasan Marxisme sejak Marx berada di Paris pada tahun 1844. Hasil penelitian Marx terhadap struktur masyarakat dalam sistem ekonomi kapitalisme, beliau menjangkakan akan terbentuk sistem komunisme di masa hadapan yang melihat dunia ini tidak lagi bersifat statik, tetapi akan berlaku perubahanperubahan yang berterusan sejajar dengan teori dialektik Hegel. Menurut Marx, proses perubahan sejarah bergerak melalui komunisme primitif, feudalisme, kapitalisme, selanjutnya melalui sejarah sosialisme dan berakhir dengan komunisme. Setiap transformasi sejarah tersebut dicapai melalui revolusi kaum buruh (proletariat) yang mewakili inspirasi seluruh manusia. Melalui revolusi, kebebasan bersifat 'universal' akan dapat dicapai oleh kelas buruh, sekaligus mewakili semua umat manusia yang mahu melepaskan diri dari belenggu perhambaan. Revolusi proletariat hanya difahami dalam terminologi yang lazim kerana Marx dan Engels tidak memberikan penjelasan yang spesifik terhadap kerangka komunisme masa hadapan (Post-Revolutionary). Ini kerana Marx tidak mahu dikaitkan dengan ahli sosialis utopia yang banyak menyediakan penjelasan dalam bentuk imaginatif atau khayalan masa hadapan (Ozinga 1991: 58). 
Langkah-langkah untuk merealisasikan revolusi tersebut akan gagal sekiranya kelas proletariat tidak memiliki kuasa negara kerana ia masih diperlukan lagi bagi menggulingkan sistem kapitalisme. Marx tidak bersefahaman dengan pendirian tokoh anarkisme seperti Michael Bakunin (1814-1876) dan Josep Proudhon (1809-1865) yang mahu sistem negara dihapuskan secara total. Sebaliknya, Marx merasakan bahawa negara amat berguna untuk merealisasikan Dictatorship of Proletariat, meskipun fungsi asal negara sebagai mekanisme penindasan sesama kelas sosial. Ini kerana Marx meletakkan fungsi negara untuk tujuan peralihan sahaja terutama usaha yang menjurus ke arah sistem egalitarian iaitu sistem tanpa kerajaan, kelas dan harta (Marx \& Engels 1976: 237). Walaupun Marx menganggap kuasa negara hanya bersifat sementara, tetapi ia digunakan atas kepentingan kelas buruh yang mahu memperjuangkan persamaan hak dalam pengagihan harta.

Matlamat utama kegunaan dalam komunisme adalah proses penggantian dari kegunaan peribadi kepada kegunaan sosial. Menurut Marx dan Engels, komunisme bukan hanya merupakan harta sosial, tetapi juga meliputi konteks sistem demokrasi baru iaitu dalam bentuk komuniti atau organisasi. Melalui organisasi tersebut, Marx dapat menggambarkan kehendak manusia tanpa cenderung kepada isu pertentangan kelas dan dominasi kuasa politik. Kesannya, demokrasi bourgeois akan dibatasi oleh organisasi baru yang lebih demokratik dan realistik kerana hanya melibatkan pengurusan barang-barang berbanding pengurusan masyarakat. Ini digambarkan oleh Marx dalam karyanya The Poverty of Philosophy (n.d.: 167):

The working class in the course of its development will substitute for the old civil society an association which will exclude classes and their antagonism, and there will be no more political power properly so-called, since political power is precisely the official expression of antagonism in civil society.

Berdasarkan kenyataan di atas, Marx menyifatkan organisasi baru tersebut (kelas buruh) bukan organisasi politik, tetapi lebih bersifat demokratik supaya manusia benarbenar menjadi penguasa ke atas institusi-institusi yang mereka cipta sendiri. Organisasi tersebut juga bukan bersifat anarki kerana tidak memiliki kuasa politik, tetapi ia akan menguasai sistem masyarakat yang baru. Organisasi tersebut akan dipimpin oleh seorang ketua atau koordinator yang dilantik dari kalangan anggota-anggotanya sendiri (Ozinga 1991: 62). Hasilnya, ia akan menyumbang kepada kemajuan industri tanpa terikat dengan sistem kapitalisme yang hanya menguntungkan sebelah pihak sahaja. Mereka akan mula merangka 'rational plan' bagi mengubah taraf kehidupan masyarakat manusia dengan menghapuskan keuntungan peribadi dan membasmi gejala pembaziran (Ozinga 1991: 63). Komunisme dalam bentuk praktikal lebih menjurus ke arah pelan pengeluaran terancang kerana proses pengeluaran bukan sahaja berfungsi memenuhi keperluan manusia, tetapi juga menggambarkan kehidupan manusia yang sebenar.

Oleh sebab itu, sistem komunis dijangka akan menjamin keamanan seluruh dunia kerana Revolusi proletariat dapat menghapuskan ruang-ruang sempit dalam nasionalisme bourgeois. Justeru itu, konflik antara kelas-kelas masyarakat hanya dapat dihalang jika semua keperluan masyarakat dipenuhi, segala kemahiran dan potensi masyarakat dipacu dalam saluran sosial serta perselisihan antara kumpulan-kumpulan sosial atau individuindividu beransur pulih. Malah pendekatan mensosialisasikan alatan pengeluaran dalam 
rational plan mendatangkan manfaat kepada semua orang terutama dalam menangani gejala jenayah dan peperangan.

Berdasarkan analisis ke atas konsep kelas sosial, dapat simpulkan bahawa Marx telah melontarkan kritikan tajam ke atas sistem kapitalisme dengan melanjutkan asas falsafah dialektik dan historis sebagai wadah pejuangan menentang unsur-unsur perhambaan dalam setiap organisasi dan kelas masyarakat. Ini kerana sejarah perjuangan manusia merupakan sejarah perjuangan kelas dan negara hanya merupakan alat yang digunakan oleh kelas berkuasa untuk menindas seluruh kelas bawahan. Elemen-elemen dominasi tersebut akan berakhir dengan penghapusan sistem kapitalisme, lantas ia menandakan kemenangan kelas proletariat yang diterajui oleh kaum buruh. Kejayaan sesebuah revolusi dalam mendirikan kerajaan baru hanya bergantung penuh kepada sikap diktator proletariat yang diterjemahkan ke dalam bentuk perjuangan kelas (class struggle). Sikap diktator itu sendiri disifatkan sebagai tahap peralihan ke arah pemansuhan semua kelas masyarakat (classless) iaitu tranformasi masyarakat kapitalis ke dalam masyarakat komunis. Gambaran kapitalisme Marx cukup sempurna dengan menonjolkan keadaan buruh yang sengsara dan tertindas, lalu membayangkan masyarakat tanpa kelas melalui pembentukan 'Negara Komunis'. Oleh sebab itu, falsafah Marxisme dilihat cuba menzahirkan kesedaran asas untuk membentuk masyarakat sosialis agar hak-hak ekonomi dan politik kelas proletariat dapat dikembalikan dan menekankan keperluan memelihara kebebasan dan kemerdekaan.

\section{References}

A. Z. Abidin \& Baharuddin Lopa. 1968. Bahaya Komunisme. Jakarta: Bulan Bintang. Bobbio, N. 1979. Which Socialism? Minneapolis: University of Minnesota Press.

Hart, M. H. 1993. 100 A Ranking of the Most Influential Person in History. New York: A Citadel Press Book.

Hook, S. 1975. Revolution, Reform and Social Justice: Study in the Theory and Practice of Marxism. New York: New York University Press.

Lerner, W. 1982. A History of Socialism and Communism in Modern Times: Theorists, Activists and Humanists. London: Prentice-Hall International Inc.

Lichtheim, G. 1961. Marxism: A Historical and Critical Study. London: Routledge and Kegan Paul.

Marx, K. 1972. Karl Marx: The Essential Writing. Frederic L. (ed.) Bender. London: Westview Press

Marx, K. 1959. Capital. Jil 1. Moscow: Progress Publisher.

Marx, K. 1970. The Communist Manifesto of Karl Marx and Friedrich Engels. New York: Pathfinder Press.

Marx, K. n.d. Poverty of Philosophy. Moscow: Foreign Language Publishing House.

Marx, K. 1979. The Letters of Karl Marx. Terj. Saul K. Padover. New Jersey: Prentice-Hall Inc.

Marx, K \& Engels, F. 1976. Collected Work. New York: International Publishers.

McLellan, D. 1971. The Thought of Karl Marx: An Introduction. 2nd ed. London: The Macmillan Press Ltd.

McLellan, D. 1977. Karl Marx: Selected Writing. London: Oxford University.

Mukherjee, Subrata \& Ramaswamy, Sushila. 2000. A History of Socialist Thought: From the Precursors to the Present. New Delhi: Sage Publication Ltd.

Ozinga, R. J. 1991. Communism: Story of the Idea and Its Implementation. $2^{\text {nd }}$ ed. London: Prentice-Hall International Ltd. 